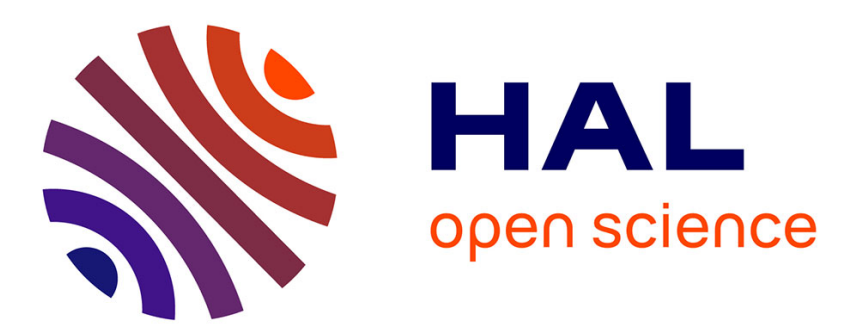

\title{
A macro- and microscopic study of adiabatic shearing extension of mode-II crack at dynamic loading
}

\author{
L. Wang, X. Dong, S. Hu, J. Yu
}

\section{To cite this version:}

L. Wang, X. Dong, S. Hu, J. Yu. A macro- and microscopic study of adiabatic shearing extension of mode-II crack at dynamic loading. Journal de Physique IV Proceedings, 1994, 04 (C8), pp.C8-465C8-470. 10.1051/jp4:1994872 . jpa-00253433

\section{HAL Id: jpa-00253433 https://hal.science/jpa-00253433}

Submitted on 1 Jan 1994

HAL is a multi-disciplinary open access archive for the deposit and dissemination of scientific research documents, whether they are published or not. The documents may come from teaching and research institutions in France or abroad, or from public or private research centers.
L'archive ouverte pluridisciplinaire HAL, est destinée au dépôt et à la diffusion de documents scientifiques de niveau recherche, publiés ou non, émanant des établissements d'enseignement et de recherche français ou étrangers, des laboratoires publics ou privés. 


\title{
A macro- and microscopic study of adiabatic shearing extension of mode-II crack at dynamic loading
}

L. Wang, X. Dong, S. Hu and J. Yu

Mechanics and Materials Science Research Centre, Ningbo University, Ningbo, Zhejiang 315211, China

\begin{abstract}
The in-plane-shear failure of a dynamic Mode-II crack is studied macro- and microscopically for a titanium alloy Ti-6Al-4V. The experimental results show that such a failure essentially results from an interaction between the precursor adiabatic shear band and the crack extended along the shear band. A two-variable $\left(\mathrm{K}_{\mathrm{II}}\right.$ and $\left.\dot{\mathrm{K}}_{\mathrm{II}}\right)$ thermo-viscoplastic instability criterion for the adiabatic in-plane-shear initiation of a Mode-II crack under dynamic loading is proposed. The theoretical predictions are in good agreement with the experimental results.
\end{abstract}

\section{INTRODUCTION}

Research on the interaction between cracks and adiabatic shear bands is of basic significance for both impact dynamics and fracture mechanics studies.

Kalthoff $[1,2]$ first reported that for a dynamic Mode-II crack, two failure modes exist. At low loading rates, the usual failure mode predominated, i.e. the maximum tensile stress criterion was observed, cracks propagating at an angle of about $70^{\circ}$ with respect to the ligament. When the loading rate exceeds a certain limit, however, a normal failure mode in which localized shear banding predominates, was observed and the cracks propagate along their original direction. Greater attention has since been extended to this problem, but the total understanding of all the physical aspects involved is still far from satisfactory.

In the present paper, the interaction between the crack as a stress/strain/strain-rate riser and the adiabatic shear band as a crack extension path-breaker is investigated both macro- and microscopically. The two control-variable thermo-viscoplastic instability criterion for adiabatic shearing suggested in [3] is incorporated into the fracture mechanics analysis and a corresponding criterion for the adiabatic in-plane-shear initiation of mode-II cracks is proposed. 


\section{EXPERIMENTAL TECHNIQUES}

The impact tests were performed on a split Hopkinson pressure bar set up but without an output bar. A plate specimen with two parallel edge cracks, as used by Kalthoff [1], is impulsively loaded by the stress waves transmitted from the input bar. The specimen with a size of $85 \mathrm{~mm}$ (length) $\mathrm{x} 170 \mathrm{~mm}$ (height) $\mathrm{x} 6.6 \mathrm{~mm}$ (thickness) lies freely on the guide way of the set up, and the distance of the two cracks is just equal to the bar diameter of $14.5 \mathrm{~mm}$. The original length of the edge cracks is about $12 \mathrm{~mm}$, with a tip radius of $0.22 \mathrm{~mm}$.

By measuring the incident and reflected stress waves propagated in the input bar, the stress waves transmitted into the specimen can be determined. In addition, the signals recorded by the straingauge, which is located near the crack tip, provide useful information about the crack tip stress/strain intensity and the crack initiation time. Thus, the stress intensification $K_{\mathrm{II}}$ and its rate with respect to time, $\dot{\mathrm{K}}_{\mathrm{II}}=\partial \mathrm{K}_{\mathrm{II}} / \partial \mathrm{t}$, can be approximately determined [4]. By varying the impact. velocity, the $K_{\mathrm{II}}$ values range from about 40 to $70 \mathrm{MPa} \sqrt{\mathrm{m}}$ and the $\dot{\mathrm{K}}_{\mathrm{II}}$ values range from $3 \times 10^{6}$ to $6 \times 10^{6} \mathrm{MPa} \sqrt{\mathrm{m}} / \mathrm{s}$.

Titanium alloy Ti-6Al-4V was used as the test material, since its higher sensibility to strain rate and adiabatic shear, has been reported [5]. After each test, the specimen was examined by optical and scanning electron microscopy. Attention was concentrated on the crack tip and the fracture surface.

\section{EXPERIMENTAL RESULTS}

For the titanium alloy tested, all the cracks, if they have extended, propagate in the original direction, i.e. at an angle of about 0 to $10^{\circ}$ with respect to the ligament of the specimen, as shown in Fig.1. The microstructural observations show that all the extended cracks propagated along the adiabatic shear band. A typical micrograph is shown in Fig.2, giving a whole picture of the interaction between crack and shear band. As can be seen from the figure, both a deformed band and a transformed band were observed. The former is generally visible, e.g. ahead of an extended crack tip, while the latter in general appears at the root part of an extended crack. Such facts are consistent with the experimental results reported in [6], that is, the transformed shear band develops from the deformed band.

It is worthwhile noticing that for the cracks which are subject to in-plane-shear dynamic loading but have not extended yet, there is enough evidence to prove that the localized shear band has nucleated ahead of the crack tip in the original crack direction, as shown in Fig.3. It indicates that for an in-plane-shear failure the initiation and development of the shear band ahead of the crack tip is earlier than the extension of the crack itself. From Fig.3, however, it can also be seen that the shear band induced by the stress/strain/strain-rate rising effect of the crack does not nucleate at the exact surface of the crack tip, but at a distance, say $r_{c}$, from the tip. This may be understood as being the influence of heat dissipation which is not negligible at the crack surface and consequently the adiabatic shear process, a process of thermo-viscoplastic instability under adiabatic conditions, is impossible at the surface of the crack tip, or for $r<r_{c}$.

The fracture surface of an in-plane-shear extended crack looks very different from the usual fracture surface of the mode-I crack. The fracture surface extends straight across the entire cross-section of the specimen without any shear lips, consistent with the results reported by Kalthoff and Winkler for steels [1]. The fractographic observations by scanning electron microscopy show that although most regions of the fracture surface were smeared over due to the relative frictional movement so that only a mirror-like appearance is seen, the characteristic "dimpled" appearance has been observed for both the beginning and end regions of the fracture surface, as shown in Fig.4. Thus, it is identified again that the crack undoubtedly propagates along the precursory, highly localized 


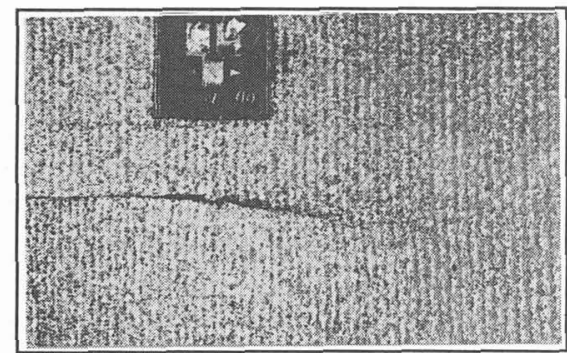

Fig. 1 Dynamic in-plane-shear extended crack for Ti-6Al-4V (x6)

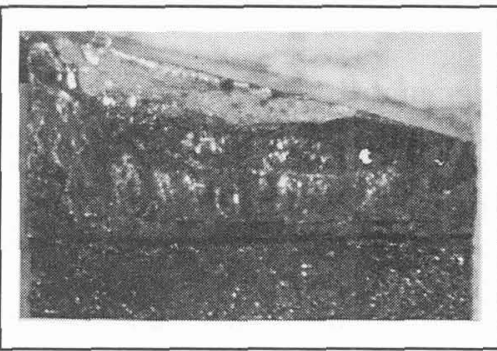

Fig. 5 Micrograph of fracture surface showing concave crack front (x9)

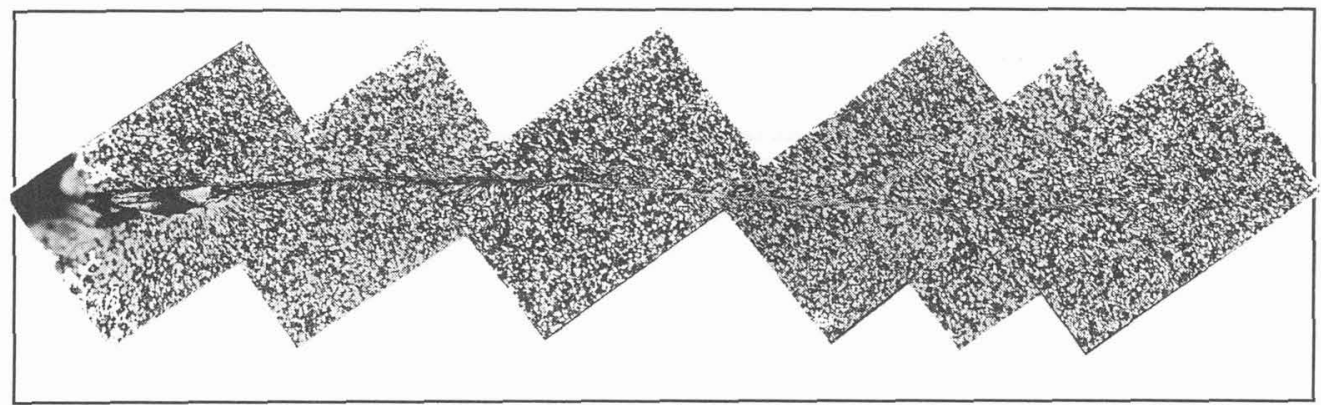

Fig. 2 Micrograph of the specimen dynamically loaded at $V_{0}=93 \mathrm{~m} / \mathrm{s}$, showing an interaction between crack and adiabatic shear band ( $x 250$ )

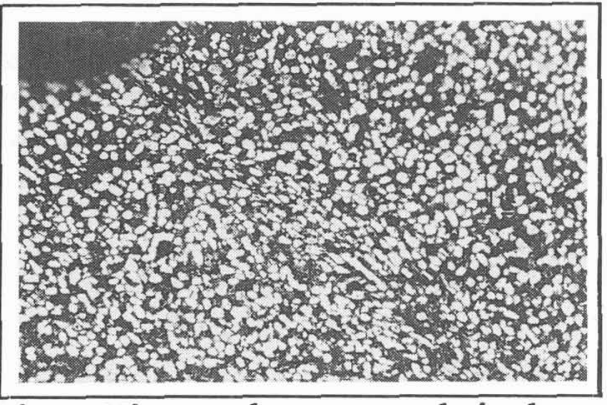

Fig. 3 Micrograph near a crack tip showing nucleation of an adiabatic shear band (x500)

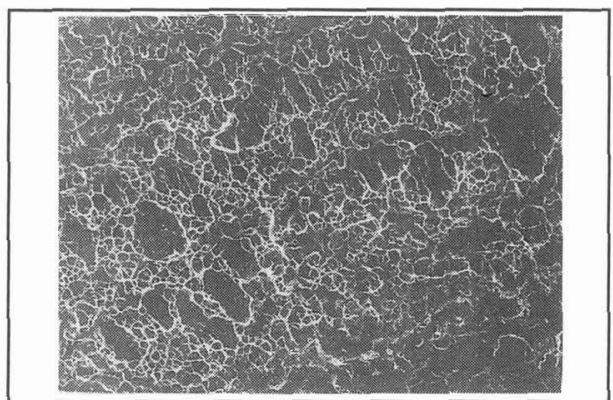

Fig. 4 SEM fractograph for a Mode-II crack extended along shear band, showing dimpled appearance (x1130) 
and largely deformed shear band. Moreover, it was found that the extended crack length at the edge is longer than in the centre. In other words, the extended crack for an in-plane-shear failure dominated by adiabatic shearing is characterized by a concave front, as shown in Fig.5, in sharp contrast with the usual convex crack front for a mode-I failure. This fact indicates that the crack tip shear stress, which is more intensive under plane-stress in the edge region than under plane-strain in the central region, plays a leading role for an in-plane-shear failure. This is easy to understand, since the in-plane-shear failure is inseparably coupled with shear banding.

Furthermore, it was found that once the impact velocity, $V_{o}$, is greater than a threshold velocity, the extended crack length measured on the specimen surface, $\Delta a$, increases with increasing $V_{o}$, as shown in Table 1. Note that for the Hopkinson Pressure Bar technique, both the loading amplitude and the strain-rate increase with increasing $V_{o}$. Thus, the experimental results listed in Table 1 imply that the fracture behaviour of an in-plane-shear crack will depend on both the applied stress and strain-rate, or in terms of fracture mechanics parameters, both the stress intensification $K_{\mathrm{II}}$ and the stress intensity factor rate $\dot{\mathrm{K}}_{\mathrm{II}}$.

Table 1 The Dependence of $\Delta a(m m)$ on $V_{0}(m / s)$

\begin{tabular}{|l|l|l|l|l|l|l|l|l|l|l||}
\hline $\mathrm{V}_{\mathrm{o}}$ & 43.0 & 45.1 & 50.6 & 56.6 & 64.0 & 69.8 & 72.3 & 75.0 & 77.0 & 93.1 \\
\hline$\Delta \mathrm{a}$ & $\mathrm{IV}$ & $\mathrm{IV}$ & $\mathrm{IV}$ & $\mathrm{IV}$ & 1.0 & 0.5 & 2.0 & 1.0 & 1.8 & 2.5 \\
\hline
\end{tabular}

* IV-invisible

Using the dynamic measurements from the Hopkinson input bar and the strain-gauge near the crack tip [4], the corresponding values of $\mathrm{K}_{\mathrm{II}}$ and $\dot{\mathrm{K}}_{\mathrm{II}}$ for the initiation of an in-plane-shear crack, i.e. $\left(\mathrm{K}_{\mathrm{II}}\right)_{\mathrm{i}}$ and $\left(\dot{K}_{I I}\right)_{i}$, were determined. The results are given in Fig. 6 which shows that the value of $\left(\dot{K}_{I I}\right)_{i}$ decreases with an increasing value of $\left(\mathrm{K}_{\mathrm{II}}\right)_{\mathrm{i}}$, and vice versa.

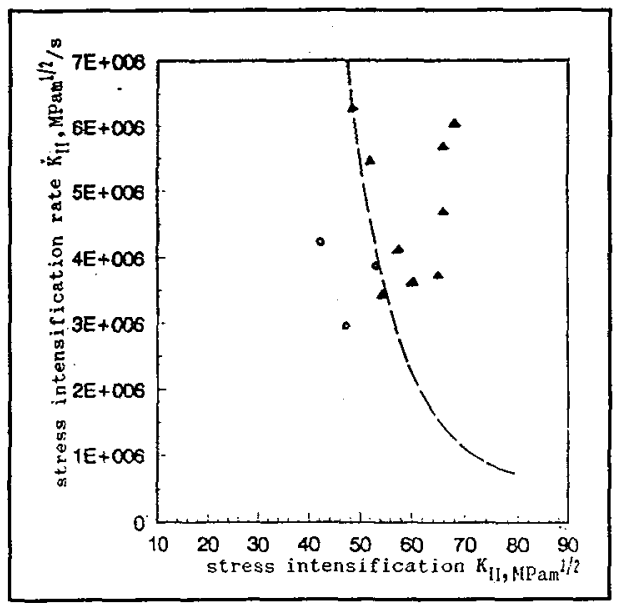

Fig. 6 Dependence of the adiabatic in-plane-shear initiation of a dynamic Mode-II crack on stress intensification $\mathrm{K}_{\mathrm{II}}$ and stress intensification rate $\dot{\mathrm{K}}_{\text {II }}$.

Experimental results:

- -...- crack extension invisible

A -..-- crack extension visible

Theoretical curve:

\section{CRITERION OF ADIABATIC IN-PLANE-SHEAR INITIATION FOR DYNAMIC MODE-II CRACK}

The experimental results mentioned above indicate that the adiabatic in-plane-shear extension of a dynamic Mode-II crack results essentially from an interaction between the crack as a stress/strain/ 
strain-rate riser and the shear band as a crack extension path-breaker. Thus, the critical condition for the in-plane-shear initiation of a dynamic Mode-II crack should be related to the criterion for adiabatic shearing.

A strain- and strain-rate-dependent thermo-viscoplastic instability criterion for adiabatic shearing was suggested in [3] for uncrackled materials. For a thermo-viscoplastic material with a constitutive relation of the form

$$
\sigma-\left(\sigma_{0}+E_{1} \epsilon\right)\left(1+g \ln \frac{\dot{\varepsilon}}{\dot{\varepsilon}_{0}}\right)\left(1-\alpha \frac{T-T_{\theta}}{T_{\theta}}\right)
$$

the corresponding critical condition for adiabatic shearing is

$$
\left(1+g \ln \frac{\dot{\epsilon}}{\dot{\epsilon}_{0}}\right)\left(\frac{\sigma_{0}}{E_{1}}+\epsilon\right)\left(A-\frac{\alpha \beta E_{1}}{\rho C T_{e}} \epsilon\right)=1
$$

where $\sigma, \epsilon$ and $\dot{\epsilon}$ are stress, strain and strain-rate, respectively, $\rho$ is the density, $c$ is the specific heat of the material, $B$ is the fraction of viscoplastic work converted to heat, $\mathrm{E}, g$ and $\alpha$ characterize the strain hardening, the strain-rate hardening and the thermal softening, respectively, and $\sigma_{0}$ and $\dot{\epsilon}_{\mathrm{o}}$ are the characteristic stress and strain-rate, respectively, for a quasi-static test at an environmental temperature of $T_{e}$. The integral constant $A$ characterizes the specific state in an adiabatic shear process.

By introducing the effective stress, strain and strain-rate defined respectively as

$$
\bar{\sigma}=\sqrt{\frac{3}{2} S_{i j} S_{i j}}, \quad \bar{\epsilon}-\sqrt{\frac{2}{3} e_{i j} e_{i j}}, \quad \dot{\bar{\epsilon}}=\frac{\partial \bar{\epsilon}}{\partial t}
$$

where $S_{i j}$ is the deviatoric stress and $e_{i j}$ the deviatoric strain, Eq.(2) can be generalised to

$$
\left(1+g \ln \frac{\dot{\bar{\epsilon}}}{\dot{\epsilon}_{0}}\right)\left(\frac{\sigma_{0}}{E_{1}}+\bar{\varepsilon}\right)\left(A-\frac{\alpha \beta E_{1}}{\rho C T_{e}} \overline{\bar{\epsilon}}\right)-1
$$

On the other hand, since the adiabatic shear band is characterised by a highly localized deformation, the stress field for a Mode-II crack discussed here can be given approximately by elastic fracture mechanics, whence

$$
\sigma_{x}=-\frac{K_{I I}}{\sqrt{2 \pi I}} \sin \frac{\theta}{2}\left[2+\cos \frac{\theta}{2} \cos \frac{3 \theta}{2}\right], \quad \sigma_{y}=\frac{K_{I I}}{\sqrt{2 \pi r}} \sin \frac{\theta}{2} \cos \frac{\theta}{2},
$$

while, in terms of the von Mises yield criterion, the corresponding small plastic zone radius, $r_{p}$, can be determined by the following equation

$$
r_{p}=\frac{1}{2 \pi}\left(\frac{K_{I I}}{\sigma_{s}}\right)^{2}\left[(1-2 v)^{2} \sin ^{2} \frac{\theta}{2}+3\left(1-\frac{3}{4} \sin ^{2} \theta\right)\right]
$$

The strain field at the elastic-plastic boundary $r_{p}$ can be obtained by Hooke's law:

$$
\left(\epsilon_{x}\right)_{b}=\frac{1}{E}\left[\sigma_{x}-v\left(\sigma_{y}+\sigma_{z}\right)\right]_{x-x_{p}}, \quad\left(\epsilon_{y}\right)_{b}=\frac{1}{E}\left[\sigma_{y}-v\left(\sigma_{x}+\sigma_{z}\right)\right]_{x-x_{p}},\left(\gamma_{x y}\right)_{b}=\frac{2(1+v)}{E} \sigma_{x y_{x-x_{p}}}
$$

Assuming that the strain in the plastic zone is inversely proportional to the distance, $r$, from the crack tip, as suggested by McClintock [7] for the plastic strain distribution of a Mode-III crack, that is,

$$
\left(\epsilon_{x}\right)_{p}=\frac{r_{p}}{r}\left(\epsilon_{x}\right)_{b}, \quad\left(\epsilon_{y}\right)_{p}=\frac{r_{p}}{r}\left(\epsilon_{y}\right)_{b}, \quad\left(\gamma_{x y}\right)=\frac{r_{p}}{r}\left(\gamma_{x y}\right)_{b}, \text { for } 0<r<r_{p}
$$

Substituting Eqs.(8),(7),(6) and (5) into Eq.(3), the corresponding effective strain and strain-rate can be obtained. For the in-plane-shear direction, $\theta=0^{\circ}$, they reduce to 


$$
\bar{\epsilon}-\frac{(1+v) K_{I I}^{2}}{\pi E \sigma_{s} r}, \quad \bar{\epsilon}-\frac{2(1+v) K_{I I} \dot{K}_{I I}}{\pi E \sigma_{s} r}, \text { for } \theta=0
$$

Since it was found that a shear band nucleates at a distance $r_{c}$ from the crack tip, as shown in Fig.3, substituting Eq.(9) into Eq.(4) and taking $r=r_{c}$, a two control-variable criterion of adiabatic in-plane-shear initiation for dynamic Mode-II crack is finally obtained in terms of $K_{\mathrm{II}}$ and $\dot{\mathrm{K}}_{\mathrm{II}}$ :

$$
\left(1+g \ln \frac{2(I+v) K_{I I} \dot{K}_{I I}}{\pi E \sigma_{0} \dot{\epsilon}_{0} I_{c}}\right)\left(\frac{\sigma_{0}}{E_{1}}+\frac{(1+v) K_{I I}^{2}}{\pi E \sigma_{0} I_{c}}\right)\left(A-\frac{\alpha \beta E_{1}}{\rho C T_{\theta}} \frac{(I+v) K_{I I}^{2}}{\pi E \sigma_{0} I_{c}}\right)=1,
$$

where the elastic strain is neglected.

For the tested Ti-6Al-4V, it was found experimentally that $r_{c}=0.8 \mu \mathrm{m}$ and $\mathrm{A}=0.86$. The corresponding theoretical, critical $\dot{K}_{\mathrm{II}}-\mathrm{K}_{\mathrm{II}}$ curve is shown in Fig.6. It can be seen that the theoretical model is in good agreement with the experimental results.

\section{CONCLUSIONS}

The in-plane-shear extension of a dynamic Mode-II crack essentially results from an interaction between the precursor adiabatic shear band and the crack extended along the shear band. Briefly speaking, firstly, promoted by the highly concentrated dynamic stress/strain/strain-rate field near the crack tip, a highly localized shear band is initiated ahead of the crack in the original crack direction; voids then appear and grow within the shear band ahead of the crack tip; finally, the crack propagates along the shear band by a void-coalescence mechanism.

Starting from an analysis of the critical condition of thermo-viscoplastic instability for adiabatic shearing of materials and the stress/strain field of a Mode-II crack, a two-control variable $\left(\mathrm{K}_{\mathrm{II}}\right.$ and $\dot{\mathrm{K}}_{\mathrm{II}}$ ) thermo-viscoplastic instability criterion for the adiabatic shearing initiation of a dynamic Mode-II crack is proposed. The theoretical predictions are supported by the experimental results.

\section{ACKNOWLEDGEMENT}

This work is supported by the National Educational Commission Foundation of China.

\section{REFERENCES}

[1] Kalthoff, J. F., and Winkler, S., Proc. Int. Conf. on Impact Loading and Dynamic Behaviour of Materials, Bremen, May 18-22, 1987, DGM, pp. 185-196.

[2] Kalthoff, J. F., Proc. Int. Conf. on Photo-mechanics and Speckle Meteology, San Diego, Calif., Aug 16-21, 1987, pp. 531-538, and Optical Engineering 27(1988)pp. 835-840.

[3] Wang Lili, Proc. Int. Symp. on Intense Dynamic Loading and Its Effects, Sci. Press, Beijing(1986) pp.787-792.

[4] Dong Xinlong, Hu Shisheng, Yu Jilin, Wang Lili, Explosion and Shock Waves(to be published).

[5] Xu Tianping, Wang Lili, Lu Weixian, Explosion and Shock Waves 7(1987)1-8.

[6] Wang Lili, Lu Weixian, Hu Shisheng, Tang Zhiping, IUTAM Int. Symp. on Macro- and MicroMechanics of High Velocity Deformation and Fracture, Tokyo, Aug. 12-15, 1985, SpringerVerlag(1987) pp.395-406.

[7] F.A.McClintock, H.Nayeb-Hashemi, R.O.Ritchie, E.Wu and W.T.Woods, Assessing Expired Fatigue Life in large Turbine Shafts, Ornal/Sub/83-9602/1 (1983). 